\title{
Biohydrogen production with anaerobic fluidized bed reactors-A comparison of biofilm-based and granule-based systems
}

\author{
Zhen-Peng Zhang ${ }^{a, b}$, Kuan-Yeow Show ${ }^{c, *}$, Joo-Hwa Tay ${ }^{a, b}$, David Tee Liang ${ }^{b}$, Duu-Jong Lee ${ }^{d}$ \\ ${ }^{a}$ School of Civil and Environmental Engineering, Nanyang Technological University, Singapore \\ ${ }^{\mathrm{b}}$ Institute of Environmental Science and Engineering, Nanyang Technological University, Singapore \\ ${ }^{\mathrm{c}}$ Faculty of Engineering and Science, University of Tunku Abdul Rahman, Malaysia \\ ${ }^{\mathrm{d}}$ Department of Chemical Engineering, National Taiwan University, Taipei, ROC
}

\section{A R T I C L E I N F O}

Article history:

Received 15 June 2007

Accepted 28 September 2007

Available online 26 November 2007

Keywords:

Biohydrogen

Anaerobic fluidized bed reactor

Biofilm

Granule

\begin{abstract}
A B S T R A C T
Biofilm sludge and granular sludge were used to convert glucose into hydrogen in two anaerobic fluidized bed reactors (AFBRs) operated at a $\mathrm{pH}$ of 5.5 and $37^{\circ} \mathrm{C}$. Influence of hydraulic retention time (HRT) and glucose concentration on hydrogen production in the reactors was examined at a constant organic loading rate (OLR) of $40 \mathrm{~g}$-glucose/L h by varying HRT from 0.125 to $3 \mathrm{~h}$ and glucose concentration from 5 to $120 \mathrm{~g} / \mathrm{L}$. Consistent and comparable hydrogen production was achieved in both reactors as HRT was controlled within the range of $0.25-0.75 \mathrm{~h}$, corresponding to glucose concentrations of $10-30 \mathrm{~g} / \mathrm{L}$. The hydrogen yield obtained in both reactors ranged between 0.4 and $1.7 \mathrm{~mol}-\mathrm{H}_{2} / \mathrm{mol}$-glucose, with a maximum yield occurring at an HRT of $0.25 \mathrm{~h}$ and a glucose concentration of $10 \mathrm{~g} / \mathrm{L}$. At the same HRT and glucose concentration, hydrogen production rate also reached the maximum values of 7.6 and $6.6 \mathrm{~L}-\mathrm{H}_{2} / \mathrm{L} \mathrm{h}$ in biofilm reactor and granule reactor, respectively. It was noted that biofilm was washed out substantially in biofilm reactor and reactor biomass was replaced by granules during the operation of 50 days. No apparent variation in hydrogen production was observed as the biofilm was replaced by granules. This is likely attributed to the fact that the biomass concentration was predominantly maintained within a narrow range of 34-37 g-VSS/L for both reactors. As compared with carrier-based biofilm reactor, granule-based reactor indicated an advantage of better biomass retention without subject to washout of support carriers.

c) 2007 International Association for Hydrogen Energy. Published by Elsevier Ltd. All rights
\end{abstract}

reserved.

\section{Introduction}

Over the past two decades, anaerobic hydrogen fermentation has attracted worldwide attention [1,2]. This is largely due to the soaring concerns on environmental deterioration and sustainability derived from the utilization of conventional fossil fuels and on the potential of hydrogen as an ideal alternative. Currently, laboratory-scale studies on anaerobic hydrogen fermentation technology are being conducted by a large number of research groups in different countries over the world [3-6]. This technology exhibits positive features in hydrogen production such as high production rate, low energy demand, easy operation and high sustainability. However, it is yet to compete with those thermochemical

*Corresponding author. Fax: +6060341079803.

E-mail addresses: kyshow2003@yahoo.com, ckyshow@ntu.edu.sg (K.-Y. Show).

0360-3199/\$ - see front matter ๔ 2007 International Association for Hydrogen Energy. Published by Elsevier Ltd. All rights reserved. doi:10.1016/j.ijhydene.2007.09.048 
processes converting hydrogen from fossil fuels in cost, performance or reliability [7]. As a result, current research of anaerobic hydrogen fermentation has been focused on improving microbial hydrogen conversion rate and unit volumetric production rate. The former could be achieved by screening efficient hydrogen-producing bacteria and optimizing the operational conditions, while the latter is substantially influenced by the reactor biomass retention. To achieve such purposes, immobilization processes of hydrogen-producing culture have become most popular and have been developed extensively, due to the elevated biomass retention as compared to suspended-cell systems [8,9].

Recent studies found that favorable immobilized-cell anaerobic hydrogen production systems include upflow anaerobic sludge blanket (UASB) reactor [10], granule-based continuous stirred tank reactor (CSTR) [11], fixed or packed bed reactor $[1,12]$, anaerobic fluidized bed reactors (AFBR) $[13,14]$ and tricking biofilter [15]. Overall, these immobilization technologies are mainly based on granulation process or biofilm attachment process. Relatively high unit volumetric production rates were found in these systems as a consequence of the elevated biomass retention. According to reported works, hydrogen production rate was achieved the respective peaks at $7.30 \mathrm{~L} / \mathrm{Lh}$ in a granular sludge bed reactor [16], $0.25-1.70 \mathrm{~L} / \mathrm{L} \mathrm{h}$ in fixed-bed reactors $[1,12,17,18], 0.16-0.28 \mathrm{~L} / \mathrm{L} \mathrm{h}$ in UASB reactors [9,19], 0.54 L/L h in a granule-based CSTR [11], 2.32L/L $\mathrm{h}$ in an AFBR [14] and 1.01 L/L h in a thermal trickling biofilter [15]. It is obvious that substantial differences in hydrogen production rate still remain among these immobilized-cell processes, which could be attributed to the difference in the microbial population and the operating conditions. On the other hand, it is likely that the reactor performance is also related to the process characteristics per se, such as reactor and immobilized-cell configurations. However, systematic studies regarding process comparison between granule-based and biofilm-based processes under identical operating conditions have been scarcely reported.

In the present study, cell immobilization was achieved by formation of biofilm and self-flocculated granules in AFBRs. Process performance with respect to hydrogen production in granule-based reactor and biofilm-based reactor was assessed by varying hydraulic retention time (HRT) and substrate concentration simultaneously at a consistent organic loading rate (OLR).

\section{Materials and methods}

\subsection{Inoculum and substrate}

The granular sludge and biofilm used in the present study were developed by a procedure of acid incubation on the acclimated seed sludge with an initial concentration of $6.14 \mathrm{~g}$ VSS/L. Anaerobically digested sludge obtained from a wastewater treatment plant in Singapore was used as inoculum, which was subject to a pretreatment of heat and acidification, and was acclimated with glucose $(10 \mathrm{~g}$-glucose/L) in an anaerobic CSTR at pH 5.5 and an HRT of 50-6h for more than 2 months. Detailed procedures of pretreatment and acclimation of the seed sludge were described in a previous study [2].
Granular activated carbon (GAC) was used as the support medium for biofilm attachment, whose physical characteristics had been described in a previous study [14]. The substrate used for hydrogen fermentation consisted of glucose ranging from 5 to $120 \mathrm{~g} / \mathrm{L}$, and nutrients at a constant organic carbon to nutrient ratio as described in previous studies $[2,14]$ throughout the study. Moreover, sodium bicarbonate was added at a concentration of $5 \mathrm{~g} / \mathrm{L}$ in feed solution.

\subsection{Experimental setup and operation}

Two identical column reactors, each mounted with a threephase separator, were operated as AFBRs. A schematic diagram of the reactor is shown in Fig. 1 . The reactor consisted of a glass tubular section of $40 \mathrm{~mm}$ internal diameter and $500 \mathrm{~mm}$ height with a conic bottom. An upper section of $80 \mathrm{~mm}$ internal diameter and $150 \mathrm{~mm}$ length was mounted to minimize carry over of suspended particles into the effluent and also to serve as a gas holder. A $40 \mathrm{~mm}$ height fixed-bed of grass beads was located at the conic bottom, serving as a distributor for incoming liquid. Each reactor had a total volume of $1.4 \mathrm{~L}$ inclusive of reaction-zone volume of $0.6 \mathrm{~L}$. The column has four sampling ports located at 50,120, 250 and $400 \mathrm{~mm}$ above the reactor bottom. These ports were used to extract liquid and bioparticle samples along the reactor. The mixed slurry was recycled through a recycling pump connecting the outlet located at settling section and feed inlet at a constant recycling rate of $200 \mathrm{~mL} / \mathrm{min}$. Culture $\mathrm{pH}$ in the reactor was controlled at $5.5 \pm 0.2$ by automatic

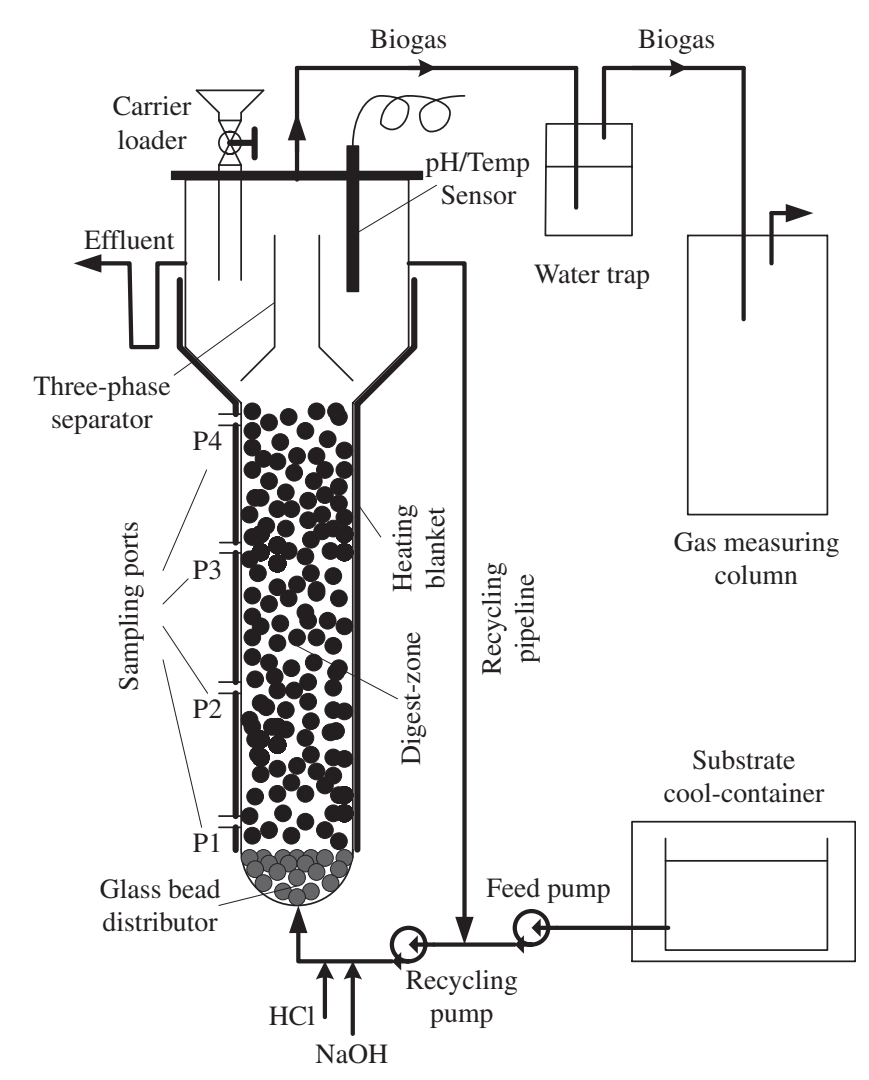

Fig. 1 - Schematic diagram of the anaerobic fluidized bed reactor system. 
titration using respective peristaltic pumps connecting to an integrated controller with $4 \mathrm{M} \mathrm{NaOH}$ and $4 \mathrm{M} \mathrm{HCl}$. The reactors were operated at a consistent temperature of $37^{\circ} \mathrm{C}$ by a heating blanket.

The AFBRs designated as granule reactor and biofilm reactor were operated to evaluate reactor performance under the identical conditions. The reactors were run with HRTs of $0.25,0.5,0.75,1,1.5,2,3$ and $0.125 \mathrm{~h}$ in series, corresponding to influent glucose concentrations of $10,20,30,40,60,80,120$ and $5 \mathrm{~g} / \mathrm{L}$ to maintain a constant OLR of $40 \mathrm{~g}$-glucose/L h. The HRT was calculated on the basis of the total reactor volume, while the OLR was computed from the concentration of glucose loaded to the reactor per unit HRT. Pseudo-steadystate conditions at each HRT level were considered attained when the biogas production and glucose conversion rate were relatively consistent within $5 \%$ for three consecutive days. Evaluation of the system performance was carried out during the pseudo-steady-state conditions.

\subsection{Analytical methods}

Biogas flow and production were measured using water displacement method, and biogas volume was calibrated to a temperature of $25^{\circ} \mathrm{C}$ and pressure of 1 atm condition. The biogas composition was analyzed by a gas chromatography (Varian 4900, USA) equipped with a thermal conductivity detector. Hydrogen was analyzed using a Molsieve 5A Plot column with argon as carrier gas set at $60^{\circ} \mathrm{C}$; Methane and carbon dioxide were analyzed using a Propac Q column with helium as carrier gas also set at $60^{\circ} \mathrm{C}$. Glucose concentration was determined following the phenol-sulfuric acid method reported by Dubois et al. [20]. Measurements of SS and VSS were performed in accordance with the Standard Methods [21].

\section{Results and discussion}

\subsection{Production of hydrogen}

Fig. 2 illustrates that the impacts of HRT and glucose concentration on the hydrogen production in granule reactor and biofilm reactor at a given OLR of $40 \mathrm{~g}$-glucose/L h. The biogas produced consisted of hydrogen and carbon dioxide, and was free of methane during the experimental period. Similar level of hydrogen content at each HRT was observed in both granule reactor and biofilm reactor as illustrated in Fig. 2a. Hydrogen content increased slightly from 38\% to $48 \%$ of the biogas produced as the HRT increased from 0.125 to $3 \mathrm{~h}$. These values were much lower than that (60-64\%) obtained in reported studies with the same seed sludge $[2,22]$. It is likely that part of the carbon dioxide was released from sodium bicarbonate when neutralized by organic acids produced during the hydrogen fermentation and hence reduced the associated content of hydrogen gas.

In general, both granule reactor and biofilm reactor indicated close performance in hydrogen production. Hydrogen yield and hydrogen production rate increased as the HRT was shortened from 3 to $0.25 \mathrm{~h}$ and decreased substantially with further reduction in HRT to $0.125 \mathrm{~h}$ (Fig. $2 \mathrm{~b}$ and c). While

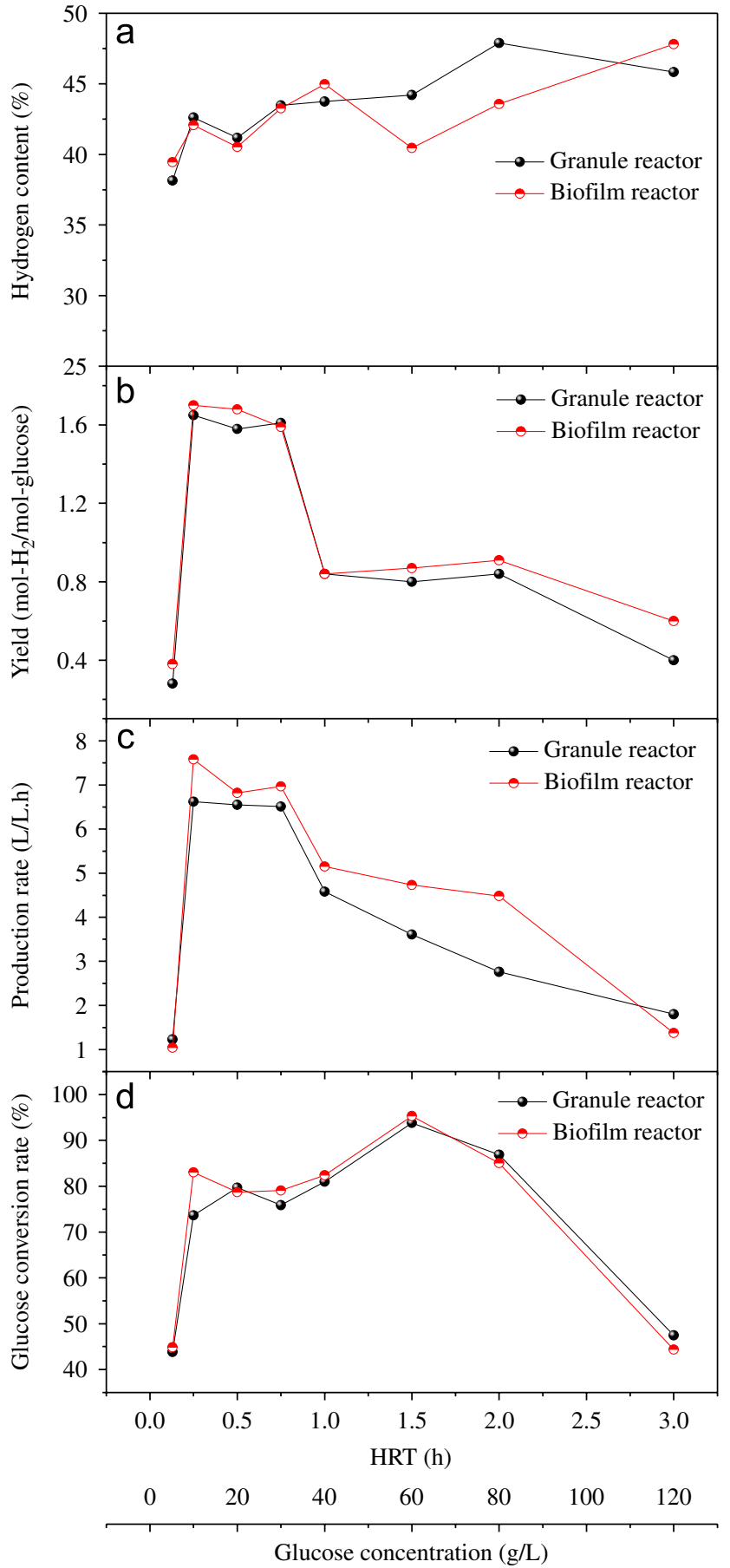

Fig. 2 - Effects of HRT and glucose concentration on (a) hydrogen content, (b) hydrogen yield, (c) hydrogen production rate and (d) glucose conversion rate in granule reactor and biofilm reactor.

hydrogen yield at a given HRT was comparable for both reactors, a slightly higher hydrogen production rate was found in the biofilm reactor. The hydrogen yield obtained in both reactors was within a range of $0.4-1.7 \mathrm{~mol}-\mathrm{H}_{2} / \mathrm{mol}-$ glucose with the maximum yield occurring at a HRT of $0.25 \mathrm{~h}$ and a glucose concentration of $10 \mathrm{~g} / \mathrm{L}$, in which hydrogen production rate also reached the respective maximum values of 7.6 and $6.6 \mathrm{~L}-\mathrm{H}_{2} / \mathrm{Lh}$ in biofilm reactor and 
granule reactor. It was noted that a $1.1 \mathrm{~L}-\mathrm{H}_{2} / \mathrm{Lh}$ increase in hydrogen production rate was achieved in biofilm reactor under the optimum operating conditions as compared with granule reactor. This was due to the relatively high glucose conversion rates obtained in biofilm reactor as shown in Fig. 2d. Glucose conversion rates in biofilm reactor and granule reactor were determined to be around $80 \%$ at HRT ranging between 0.25 and $1.0 \mathrm{~h}$, corresponding to glucose concentration of $10-40 \mathrm{~g} / \mathrm{L}$. Significant decrease in glucose conversion rate was noted when the HRT and glucose concentration reduced to $0.125 \mathrm{~h}$ and $5 \mathrm{~g} / \mathrm{L}$, at which $44 \%$ and $54 \%$ of the influent glucose were utilized. Such a decrease in glucose conversion rate was also found when the HRT increased to $3 \mathrm{~h}$, corresponding to an increase in glucose concentration to $120 \mathrm{~g} / \mathrm{L}$.

Based on the above observation and on hydrogen yield and hydrogen production rate, the optimal operating HRT and glucose concentration were determined to range between 0.25 and $0.75 \mathrm{~h}$ and 10 and $30 \mathrm{~g} / \mathrm{L}$ for biofilm reactor and granule reactor, respectively. Shortening the HRT to $0.125 \mathrm{~h}$ caused inferior hydrogen fermentation, and an HRT of $0.25 \mathrm{~h}$

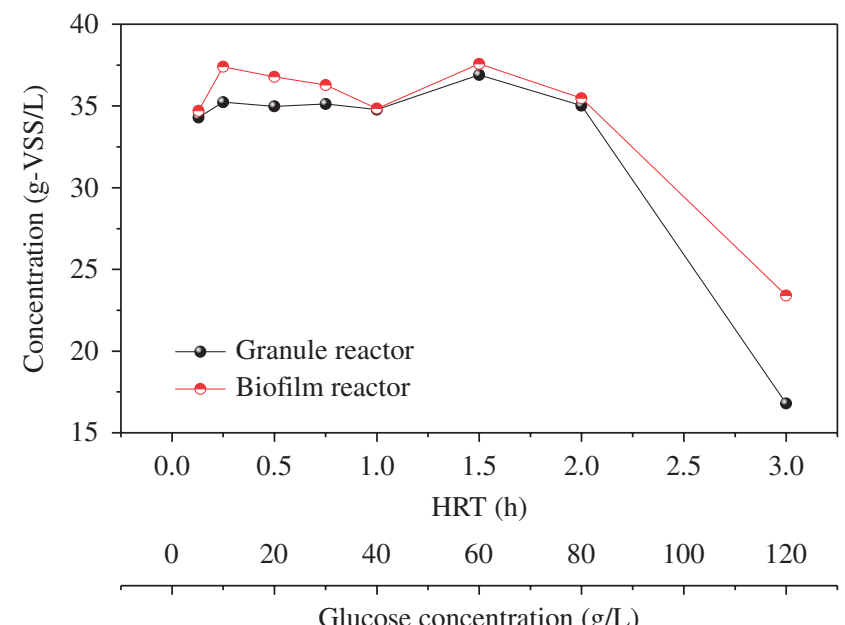

Glucose concentration (g/L)

Fig. 3 - Effects of HRT and glucose concentration on biomass concentration in granule reactor and biofilm reactor.
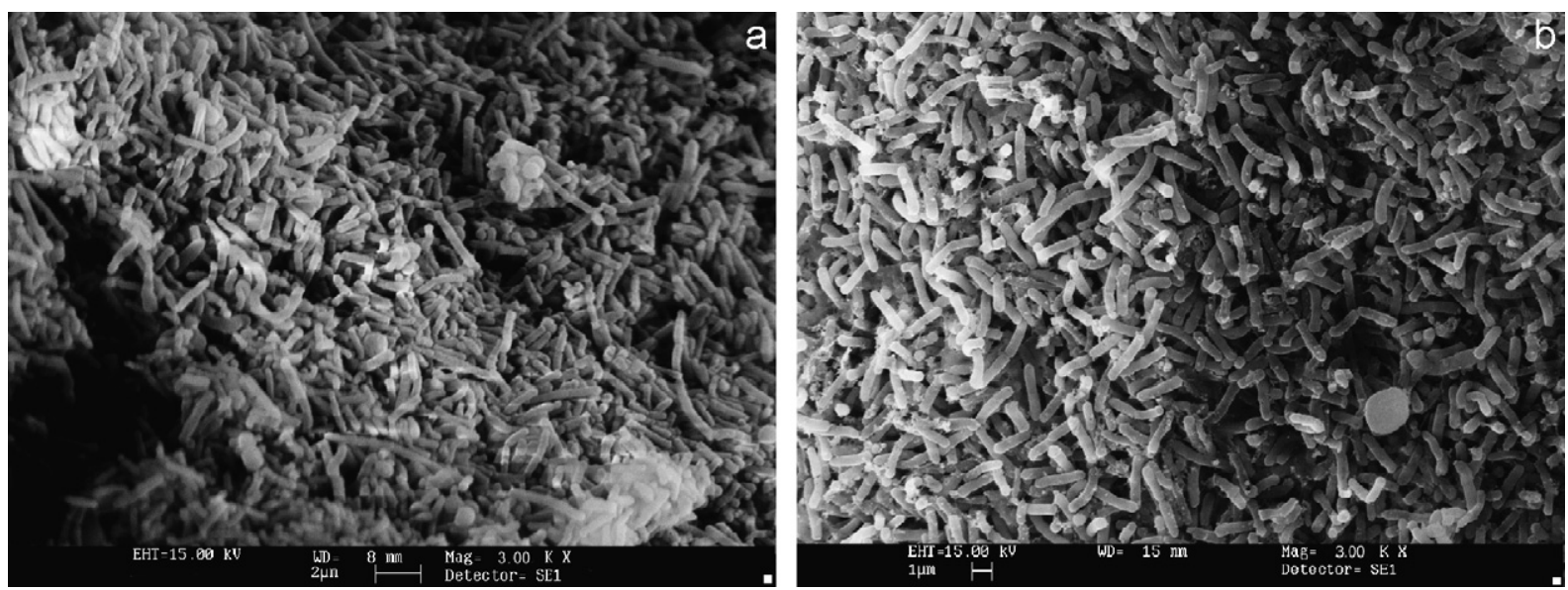

was considered to be critical for the AFBRs, regardless of biofilm or granule system. This value was at least one-fold lower than the HRT required by other hydrogen production bioreactors at optimum hydrogen production. For examples, Lee et al. [16] found a substantial decrease in hydrogen yield and hydrogen production rate when a granule-based column reactor was operated at an HRT of $0.25 \mathrm{~h}$ as compared with the peaks achieved at $0.5 \mathrm{~h}$ HRT. Furthermore, it was recognized that the HRT ranged between 1 and $2 \mathrm{~h}$ for other immobilizedcell biosystems, i.e. UASB reactor [19] and packed-bed reactor [12] for optimum hydrogen production. It is speculated that a lower critical HRT obtained is attributed to the good mixing characteristics of bioparticles under fluidization state. On the other hand, while both reactors were operated at a glucose concentration of up to $30 \mathrm{~g} / \mathrm{L}$, satisfactory hydrogen production could still be achieved. This implied that critical glucose concentration was around $30 \mathrm{~g} / \mathrm{L}$ for the present system as significant reduction in hydrogen yield and hydrogen production rate occurred when glucose concentration was further increased to $40 \mathrm{~g} / \mathrm{L}$ for both reactors. This critical concentration of substrate was in agreement with the reported values for the granule- or biofilm-based processes $[8,14]$. It was noted that inhibitory concentration of substrate on acidogenic bacteria was estimated to be about 5-6g-glucose/L in the suspended cultures $[23,24]$. These results imply that microorganisms in the biofilm and granule biomass matrix might react more actively under a stressful environment in comparison to the biomass in the form of suspension.

\subsection{Biomass retention}

Obviously, no apparent difference in hydrogen production between granule reactor and biofilm reactor was reported in the present study. This is largely owing to the relatively consistent and comparable biomass concentration maintained in both reactors as shown in Fig. 3. Furthermore, scanning electron microscope (SEM) images as illustrated in Fig. 4 reveal similar microbial composition, i.e. rod-shaped bacteria predominated on the surface of the biofilm and granules. Biomass concentration in the reaction zone was

Fig. 4 - Microbial composition on the surface of (a) biofilm and (b) granules. 


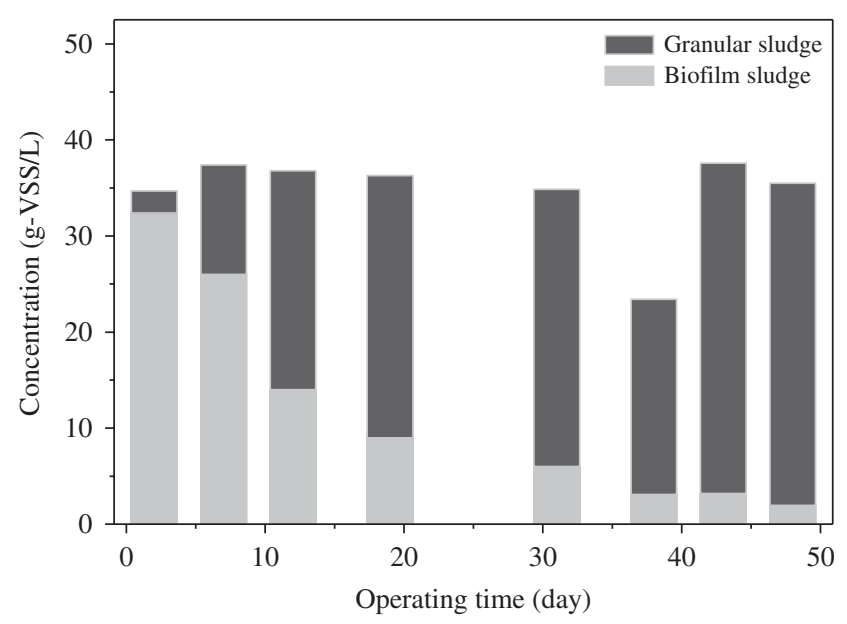

Fig. 5 - Distribution profile of biofilm sludge and granule sludge in biofilm reactor.

maintained consistently within the ranges of $61-65$ g-VSS/L and 61-66g-VSS/L at HRTs between 0.125 to $2 \mathrm{~h}$ for the granule reactor and biofilm reactor, respectively. Considering the total volume of reactor $(1.4 \mathrm{~L})$, overall biomass concentration corresponded to 34.7-36.9 and 34.3-37.6 g-VSS/L, respectively. This indicated that adding support media in biofilm reactor did not reduce the biomass retention as compared with the granule-based reactor. Nevertheless, substantial decrease in overall biomass concentration to 23.4 and $16.8 \mathrm{~g}$ VSS/L was noted in biofilm reactor and granule reactor, respectively, at an HRT of $3 \mathrm{~h}$ and a glucose concentration of $120 \mathrm{~g} / \mathrm{L}$.

Fig. 5 reveals that proportion of biofilm decreased significantly with an increase of granular biomass in the biofilm reactor. Because of a high cell yield of hydrogen-producing bacteria (0.1 g-VSS/g-glucose, data not shown) and a high OLR ( $40 \mathrm{~g}$-glucose/L h) employed, a large amount of biomass (ca. 72-127 g-VSS) was produced daily. Furthermore, it was observed that with the evolution of biofilm, the thickness of biofilm increased significantly and attachment of microorganisms to the support media might become weaker. As a result, biofilm was separated from support media due to particle-particle collision, leaving fragmented biofilm in the reactor. These fragmented biofilm eventually developed into granules which had predominated over biofilm in biofilm reactor after being operated for 50 days.

\section{Conclusions}

Two AFBRs initially loaded with biofilm and granules were operated for biohydrogen production at a constant OLR of $40 \mathrm{~g} / \mathrm{L} \mathrm{h}$, but at varying HRTs $(0.125-3 \mathrm{~h})$ and glucose concentrations $(5-120 \mathrm{~g} / \mathrm{L})$. From the results obtained, the following conclusions can be drawn.

No significant difference in hydrogen production was observed between biofilm reactor and granule reactor during the entire period of study. A consistent hydrogen production was achieved in both reactors as the HRT was controlled within the range of $0.25-0.75 \mathrm{~h}$, corresponding to glucose concentrations of $10-30 \mathrm{~g} / \mathrm{L}$. The hydrogen yield obtained in both reactors ranged between 0.4 and $1.7 \mathrm{~mol}-\mathrm{H}_{2} / \mathrm{mol}-$ glucose with the maximum yield occurring at an HRT of $0.25 \mathrm{~h}$ and a glucose concentration of $10 \mathrm{~g} / \mathrm{L}$, at which hydrogen production rate also reached the respective maximum values of 7.6 and $6.6 \mathrm{~L}-\mathrm{H}_{2} / \mathrm{Lh}$ in biofilm reactor and granule reactor.

Substantial washout of biofilm was noted in biofilm reactor, in which the biofilm was almost replaced by granules completely without affecting reactor performance during the operation of 50 days. Substantial biomass retention of up to $37 \mathrm{~g}$-VSS/L was achieved in the both reactor.

\section{R E F E R E N C E S}

[1] Rachman MA, Nakashimada Y, Kakizono T, Nishio N. Hydrogen production with high yield and high evolution rate by self-flocculated cells of Enterobacter aerogenes in a packed-bed reactor. Appl Microbiol Biotechnol 1998;49(4):450-4.

[2] Zhang ZP, Show KY, Tay JH, Liang DT, Lee DJ, Jiang WJ. Effect of hydraulic retention time on biohydrogen production and anaerobic microbial community. Process Biochem 2006;41(10):2118-23.

[3] Kim IS, Hwang MH, Jang NJ, Hyun SH, Lee ST. Effect of low pH on the activity of hydrogen utilizing methanogen in biohydrogen process. Int J Hydrogen Energy 2004;29(11): 1133-40.

[4] Ren NQ Wang BZ, Huang JC. Ethanol-type fermentation from carbohydrate in high rate acidogenic reactor. Biotechnol Bioeng 1997;54(5):428-33.

[5] Fang HHP, Liu H. Effect of $\mathrm{pH}$ on hydrogen production from glucose by a mixed culture. Bioresour Technol 2002;82(1):87-93.

[6] Lin CY, Jo CH. Hydrogen production from sucrose using an anaerobic sequencing batch reactor process. J Chem Technol Biotechnol 2003;78(6):678-84.

[7] Das D, Veziroglu TN. Hydrogen production by biological processes: a survey of literature. Int J Hydrogen Energy 2001;26(1):13-28.

[8] Wu SY, Hung CH, Lin CN, Chen HW, Lee AS, Chang JS. Fermentative hydrogen production and bacterial community structure in high-rate anaerobic bioreactors containing silicone-immobilized and self-flocculated sludge. Biotechnol Bioeng 2006;93(5):934-46.

[9] Chang FY, Lin CY. Biohydrogen production using an up-flow anaerobic sludge blanket reactor. Int J Hydrogen Energy 2004;29(1):33-9.

[10] Yu HQ Mu Y. Biological hydrogen production in a UASB reactor with granules. II: Reactor performance in 3-year operation. Biotechnol Bioeng 2006;94(5):988-95.

[11] Fang HHP, Liu H, Zhang T. Characterization of a hydrogenproducing granular sludge. Biotechnol Bioeng 2002;78(1):44-52.

[12] Chang JS, Lee KS, Lin PJ. Biohydrogen production with fixedbed bioreactors. Int J Hydrogen Energy 2002;27(11-12):1167-74.

[13] Wu SY, Lin CN, Chang JS. Hydrogen production with immobilized sewage sludge in three-phase fluidized-bed bioreactors. Biotechnol Prog 2003;19(3):828-32.

[14] Zhang ZP, Tay JH, Show KY, Liang DT, Lee DJ, Jiang WJ. Biohydrogen production in a granular activated carbon anaerobic fluidized bed reactor. Int J Hydrogen Energy 2007;32(2):185-91. 
[15] Oh YK, Kim SH, Kim MS, Park S. Thermophilic biohydrogen production from glucose with trickling biofilter. Biotechnol Bioeng 2004;88(6):690-8.

[16] Lee KS, Wu JF, Lo YS, Lo YC, Lin PJ, Chang JS. Anaerobic hydrogen production with an efficient carrier-induced granular sludge bed bioreactor. Biotechnol Bioeng 2004;87(5):648-57.

[17] Palazzi E, Fabiano B, Perego P. Process development of continuous hydrogen production by Enterobacter aerogenes in a packed column reactor. Bioprocess Eng 2000;22(3):205-13.

[18] Yokoi H, Maeda Y, Hirose J, Hayashi S, Takasaki Y. H-2 production by immobilized cells of Clostridium butyricum on porous glass beads. Biotechnol Tech 1997;11(6):431-3.

[19] Yu H, Zhu Z, Hu W, Zhang H. Hydrogen production from rice winery wastewater in an upflow anaerobic reactor by using mixed anaerobic cultures. Int J Hydrogen Energy 2002;27(11-12):1359-65.
[20] Dubois M, Gilles KA, Hamilton JK, Rebers PA, Smith F. Colorimetric method for determination of sugars and related substrates. Anal Chem 1956;28(3):350-6.

[21] APHA. Standard methods for the examination of water and wastewater, 20th ed. Washington, DC: American Public Health Association; 1998.

[22] Zhang ZP, Show KY, Tay JH, Liang DT, Lee DJ, Jiang WJ. Rapid formation of hydrogen-producing granules in an anaerobic continuous stirred tank reactor induced by acid incubation. Biotechnol Bioeng 2007;96(6):1040-50.

[23] Majizat A, Mitsunori Y, Mitsunori W, Michimasa N, Jun'ichiro M. Hydrogen gas production from glucose and its microbial kinetics in anaerobic systems. Water Sci Technol 1997;36(6-7):279-86.

[24] Van Den Heuvel JC, Beeftink HH. Kinetic effects of simultaneous inhibition by substrate and product. Biotechnol Bioeng 1988;31(7):718-24. 